\title{
RETRATO FALADO DO PROFESSOR: discursos que fabricam subjetividades docentes
}

SPOKEN TEACHER PORTRAIT: speechs making teaching subjectives

\author{
Maria das Graças Moura Santos ${ }^{1}$ \\ Dhemersson Warly Santos Costa \\ Carlos Augusto Silva e Silva ${ }^{3}$
}

\begin{abstract}
RESUMO: Este trabalho tem como objetivo investigar a produção de subjetividade docente dos graduandos do curso de pedagogia da Universidade Federal do Pará, Campus de Altamira/PA, a partir de discursos e seus jogos de verdade que fabricam identidades docentes. Entendendo que os discursos que produzem as subjetivações docentes são variados e são interpelados por diferentes artefatos, decidiu-se fazer um recorte em artefatos midiáticos disponibilizados nas plataformas Facebook, Youtube, Google. Além de destacar alguns desses discursos que atravessam a subjetivação docente, apresentaremos falas dos licenciandos que revelam uma naturalização desses discursos pelos graduandos. Dentre estes recortes, surgiram dois tipos de professores fabricados: mísero e messiânico. O primeiro sempre é tido como o coitado, principalmente no sentido de depreciar a profissão docente, o segundo coloca-se num lugar messiânico, o qual tem o poder nas mãos para salvar o mundo. Estas problematizações se dão por percalços relevantes, pois se sabe que nestes discursos estão contidos definições e modos de ser professor.
\end{abstract}

Palavras-chaves: Professores. Formação de professores. Produção de subjetividades.

ABSTRACT: This work aims to investigate the teaching subjectivity of undergraduate students of the pedagogy course of the Federal University of Pará, Campus de Altamira / PA, from speeches and their real games that fabricate teaching identities. Understanding that the discourses that produce the teaching subjectivities are varied and are interpellated by different artifacts, it was decided to make a cut in media artifacts made available on the platforms Facebook, Youtube and Google. In addition to highlighting some of these discourses that cross the subjectivation of teachers, we will present statements by the licenciandos that reveal a naturalization of these discourses by the undergraduates. Among these cuts, two types of fabricated teachers emerged: miserable and messianic. The former is always regarded as the poor, especially in the sense of belittling the teaching profession, the latter is placed in a messianic place, which has the power in hand to save the world. These

\footnotetext{
${ }^{1}$ Formada em Pedagogia pela Universidade Federal do Pará. Especialista em Educação, Currículo e políticas Públicas. gracamoura@gmaail.com.

${ }^{2}$ Formado em Ciências Biológicas pela Universidade Federal do Pará. Mestrando em Educação em Ciências e Matemáticas. Dhemerson-santos@hotmail.com

${ }^{3}$ Formado em Ciências Biológicas pela Universidade Federal do Pará. Mestre em Educação em Ciências e Matemáticas. Carlosaugustos02@gmail.com
} 
problematizations are due to relevant mishaps, since it is known that in these discourses are contained definitions and ways of being a teacher.

Key-words: Teachers. Teacher training. Production of subjectivities.

\title{
1. INTRODUÇÃO
}

- Quem és tu? - disse a Lagarta.

\begin{abstract}
Estas palavras não eram lá muito encorajadoras para começar uma conversa. Alice respondeu timidamente: -

Eu... senhor, eu agora neste momento nem sei. Sei, pelo menos, o que eu era, quando me levantei esta manhã, mas acho que devo ter mudado várias vezes desde essa
\end{abstract}

altura.

Carroll (2013)

O famoso diálogo entre Alice e a Lagarta no País das Maravilhas colocam em cena os modelos de subjetivação que dominaram o ocidente moderno: o sujeito e a identidade. Quem sou eu? Qual a minha nacionalidade? Qual o meu sexo biológico? Qual a cor da minha pele? Qual o meu gênero? Qual a minha orientação sexual? Qual o meu partido político? Qual a minha formação acadêmica?... Para cada resposta uma unidade, um "Eu", uma identidade, atravessada por um acoplado de discursos universais que, quando naturalizados, imprimem ao sujeito um modelo de "ser" e "estar" no mundo, uma subjetividade, embebida de códigos sociais, científicos, morais e religiosos, produzindo, fabricando, formando e formatando sujeitos.

O discurso aqui é entendido, a luz dos estudos foucaultianos, como "uma representação culturalmente construída pela realidade, não uma cópia exata" (FOUCAULT, 2012, p. 60), fabricando sujeitos, formatando-os e definindo o que se "é" e o que se deve "fazer". O discurso produz conhecimento e poder, operando por meio de categorias de saberes e conjuntos de textos que determinam o que é verdade ou mentira, certo ou errado, moral ou imoral, ético ou antiético.

Foucault (2012) explica que os discursos são exteriores ao sujeito, todavia eles fomentam a produção de subjetividades, desvelando seu funcionamento e lhe modificando, isto é, o discurso molda a subjetividade, (re)formando-a, (re)moldandoa, (re)formatando-a e (re)modelando-a em nome de uma identidade que se almeja 
construir em consonância com as leis originais desse discurso, ou seja "o sujeito está submergido por discursos e, em decorrência dessa propensão, a subjetividade é produzida pelo exterior, por meio do discurso" (PARAísO, 2012, p. 13).

Assim, o discurso fabrica contemporaneamente uma série de subjetividades: brasileiro, nordestino, negro, mulher, homossexual, evangélico, esquerdista, militante... n'identidades em produção, elas inscrevem sobre o corpo regimes de verdade que engendram o sujeito, por meio dos seus códigos, em uma identidade monolítica. Nessa mesma esteira, a figura do professor constitui-se como mais uma das infinitas subjetividades produzidas pela ordem do discurso nele é concebido e desenhado a imagem do docente que irá reverberar na sociedade, imbricando "modos" de ser, de conduzir-se e de portar-se (PARAísO, 2006).

Os discursos que interpelam os atributos de um professor são variados e estão pulverizados nos mais diversos suportes que nos interpelam rotineiramente, são "textos jornalísticos, acadêmicos, narrativas religiosas, populares, propagandas, novelas, músicas, filmes, documentos jurídicos, materiais didáticos" (CHAVES, 2016, p. 219), compõem uma malha de processos de subjetivação.

Nessa perspectiva os cursos de formação de professores são potentes máquinas de subjetivação docente, dos seus currículos emanam signos, teorias educacionais, métodos de ensino e avaliação, regras de condutas e ideologias com a finalidade de instaurar um perfil ideal do professor. Não obstante, essa subjetividade docente fabricada pelos discursos que emergem dos cursos de formação de professores disputa espaço com outras práticas discursivas como, por exemplo, a mídia que "por sua vez, também divulgam outros modos de entender o mundo, a educação, a/o docente e o currículo" (PARAísO, 2006, p. 111).

Assim, nos questionamos como é pensada a docência nesses lugares que produzem discursos? Que discursos os alunos reproduzem sobre ser professor? Que interdições são impostas a eles? Que regimes de verdade validam (e silenciam) os discursos que atravessam essa formação? Como discursos sobre docência se articulam a outros discursos forjando o ser professores? Que professores se querem formar?

Diante de tais questionamentos, nos colocamos nesta pesquisa a investigar a produção de subjetividade docente dos graduandos do curso de pedagogia da Universidade Federal do Pará, Campus de Altamira/PA, a partir de discursos e seus 
jogos de verdade que fabricam identidades docentes. Nessa perspectiva serão problematizados enunciados que formata contemporaneamente a imagem do professor.

O processo metodológico adotado e todo o esforço analítico empregado estão vinculados a utilização das teorias analíticas foucaultianas, como discurso e subjetivação. Entendendo que os discursos que produzem as subjetivações docentes são variados e são interpelados por diferentes artefatos, decidimos fazer um recorte em artefatos midiáticos (imagens, desenhos animados, filmes) disponibilizados nas plataformas Facebook, Youtube, Google. Além de destacar alguns desses discursos que atravessam a subjetivação docente, apresentaremos falas dos licenciandos que revelam uma naturalização desses discursos pelos graduandos.

Para coleta desses fragmentos textuais utilizou-se como método os complementos frasais, um documento composto com frases indutoras que devem ser complementadas. Para González Rey (2005, p. 57) este complemento frasear possibilita "a expressão de sentidos diferenciados em áreas e aspectos muito distintos da vida das pessoas." Para tal etapa foi realizada a aplicação de um "complemento frasear" em que dezessete participantes (matriculados no último ano do curso) continuaram a escrever as frases de acordo com suas ideias e referências sobre o ser professor. A coleta empírica foi realizada nos meses de fevereiro e março de 2017.

\section{O DISCURSO COMO PRODUÇÃO DE SUBJETIVIDADES}

Os discursos não são verdades acabadas (BRITO, 2015). Historicamente eles têm se modificado e contribuído de alguma forma para que outros fossem surgindo, não necessariamente igual ou similar aos anteriores, mas de acordo com a época, acredita-se que décadas, ou até séculos depois o discurso seja outro, outras verdades que atravessem outras gerações (FOUCAULT, 1996).

Por menor que seja o discurso ele relativamente está ligado ao desejo de empoderamento, é esse anseio pelo poder que leva o homem a caracterizar os discursos, criando e recriando formas de convencimento entre o discurso e a sociedade (FOUCAULT, 2012). Nesse sentido entende-se que os mais variados discursos que predominaram no decorrer da história foram também modificados de 
acordo com as necessidades da sociedade. Pois o "discurso não é simplesmente aquilo que traduz as lutas ou os sistemas de dominação, mas aquilo porque, pelo que a luta, o poder do qual nos queremos apoderar" (FOUCAULT, 1996, p. 10).

Os discursos são caracterizadores de tempos e lugares de onde ele está sendo produzido, sendo encadeado a partir deles uma série de verdades, no entanto verdades únicas e absolutas não podem ser consideradas verdades em outras épocas ou até em outros lugares, fazer uma afirmação definitiva de uma única verdade produzidas nos discursos é um tanto arriscado, pois eles mudam de acordo com cada época, lugar, grupo social.

Ora, eis que um século mais tarde, a verdade a mais elevada já não residia mais no que era o discurso, ou no que ele fazia, mas residia no que ele dizia: chegou um dia em que a verdade se deslocou do ato ritualizado, eficaz e justo, de enunciação, para o próprio enunciado: para seu sentido, sua forma seu objeto, sua relação a sua referência, (FOUCAULT, 1996, p. 15).

Em alguns momentos da historia o discurso teve a função de controlar, polir e alienar, mas também de organizar o indivíduo a determinada sociedade, assim como também tem o poder de excluir e contaminar o sujeito a determinados procedimentos capaz de engendrá-lo às práticas que favorecem o discurso do poder.

Os discursos são formados por um conjunto de enunciados que produzem e são responsáveis por disseminar verdades, mas os enunciados também podem ser articulados em outras formas diferentes, nem totalmente de forma visível e nem totalmente oculta, foram e são componentes essenciais para demarcar lugar na história e na criação de subjetividades. São esses discursos que fomentam algumas ideias que determinaram algumas praticas em determinada época da história.

[...] por mais que o enunciado não seja oculto, nem por isso é visível; ele não se oferece á percepção como portador manifesto de seus limites e caracteres. É necessária certa conversão do olhar e da atitude para poder reconhecê-lo e considerá-lo em si mesmo. Talvez ele seja tão conhecido que se esconde sem cessar; talvez seja como essas transparências familiares que, apesar de nada esconderem em sua espessura, não são apresentadas com clareza total. (FOUCAULT, 2012, p. 128).

Por isso, a cultura torna-se um lugar de produções de modos de ser, estar, pensar e conceber o mundo e suas visões. É nela que circula o que deve ser dito e pensado, na produção de significados e significantes que conduzem o sujeito a 
adequar-se a identidades e, ainda, produzindo subjetividades a partir dos mais variados processos.

Essas práticas produzidas pelos discursos inventaram ao longo da história, um jeito correto de ser homem ou mulher; um corpo ideal, o qual no caso, antigamente era o gordo e inativo, como por exemplo, o do rei, no entanto, atualmente ele, o corpo, precisa ser magro e musculoso; práticas religiosas cristãs que se modificaram ao longo da história; condutas professorais que são produzidas a partir do contexto em que se vive (CHAVES, 2016).

São práticas que foram pulverizadas em e por diferentes artefatos - mídia televisiva, músicas, escrituras religiosas, livros pedagógicos, saberes tradicionais ou científicos, entre outros- São suportes que atuam como "artefatos de subjetivação", os quais se comportam como currículos, contendo lentes já impostas de como ver o mundo, são trajetos já planejados, para que assim, apenas sigamos a melhor forma de ser homem ou mulher, professor ou aluno, religioso ou ateu.

Os discursos que atravessam tais artefatos são exteriores ao sujeito, isto porque este não é compreendido a partir de uma essência, mas, sobretudo como resultado de processos sociais e históricos, o qual é montado e desmontado em contato com diversos fatores constituintes de uma malha discursiva, assim o discurso modela a subjetividade.

A subjetividade é aqui compreendida, a luz das teorias foucaultianas, como algo que é fabricado em diferentes instâncias discursivas, a partir das relações de poder-saber. No seio dessas relações "os indivíduos são subjetivados de diferentes modos e passam a constituir a si mesmos como sujeitos" (PARAíso, 2006, p. 101).

É importante compreender que a subjetivação está para além do sujeito no centro de uma identidade fixa, monolítica, ela está para o campo da produção, isto é, o sujeito é produzido, fabricado a partir dos seus encontros com uma cultura, uma história, uma universidade, políticas, currículos... A vida, transformando-se no tempo e no espaço (SANTOS; BRITO; SILVA, 2016).

É nesse sentido que essa ideia aqui é reforçada pelas lentes foucaultianas, com a ideia de subjetivação amplamente tracejada nos seus escritos. Para Foucault (2012) a subjetivação nunca está acabada, ela se forma e forma a partir de processos produtivos, que criam práticas discursivas e o próprio sujeito que é subjetivado e fixado. Na mesma esteira, Foucault informa que o sujeito não é 
substancial, um vaso de barro, acabado, definido, moldado apenas por um único artesão, ao contrário ele é mutante, transita pela vida moldando-se pelos múltiplos discursos que $o$ atravessam.

Assim, apresentaremos agora alguns discursos que atravessam a produção de subjetividades docente, a partir do currículo do curso de Pedagogia da Universidade Federal do Pará/Altamira e de artefatos midiáticos, porém salientamos desde já que esses são apenas alguns dos discursos que interpelam a docência, cuja subjetividade demandada pelo discurso curricular e midiático "disputa espaço com demandas de outras práticas discursivas, de outros programas e de outros textos que, por sua vez, também divulgam outros modos de entender o mundo, a educação, a/o docente e o currículo (PARAíSO, 2006, p.111).

\subsection{O professor, o fabricado, o miséro}

Miserável, vil, infeliz, desventurado, pobre, coitado... Professor! Estes são alguns dos atributos que colocam em cena os processos de subjetivação do professor que, nesta pesquisa, denominamos de "Professor Miséro". A subjetividade docente nada mais é que modelos colocados de algum modo em um determinado tempo á um sujeito, que por sua vez é o objeto de transformação.

Esses modelos são constructos sociais do discurso, o qual é parte da historia e não é estático e sim móvel, é de grande importância que o entendimento perpasse as barreiras de verdades únicas, que muitas vezes se enraízam nos modelos formativos, se faz necessário que possamos ter um olhar rigoroso e peculiar para 0 ontem, hoje e o possível amanhã, nos dizeres de Brito (2015, p.1) "somos capturados e constituídos por discursos que constituem verdades em cada momento da história" fabricando modos de ser/e viver o professor miséro, por exemplo.

A identidade do professor mísero, portanto, não é estática, homogênea e universal. No Brasil ela existe na medida em que foi fabricada em meio a uma série de processos históricos, políticos e culturais que são particulares da nossa sociedade e da sua constituição. A subjetivação do professor miséro aqui é compreendida como resultado de uma série de discursos que estão ancorados na história, todavia não é nossa intenção delimitar pontos de partidas para a construção desse discurso no intuito de "descobrir o que somos" como recomenda o Oráculo de Delfos: "conhece a ti mesmo", mas, sobretudo, pensar com Foucault (1996, p. 239) e 
"Recusar o que somos", compreendendo as subjetividades docentes a partir da sua historicidade, sem, entretanto, naturalizá-las ou decifrá-las e sim "reinventar a subjetividade" (PELBART, 2000, p. 12).

Os discursos que moldaram ao longo da história a figura do professor mísero foram construídos a partir de um conjunto de enunciados. Na teoria foucaultiana o enunciado tem uma função epistemológica (o que pode ser dito?) e política (quem está autorizado a dizer? (FOUCAULT, 1996). Além dessas funções, o enunciado apresenta uma materialidade, isto é, "coisas efetivamente ditas, escritas, gravadas em algum tipo de material, passíveis de repetição ou reprodução, ativadas através de técnicas, práticas e relações sociais" (FISCHER, 2001, p. 202).

Nesta perspectiva compreendemos a produção midiática, a saber: livros, revistas, redes sociais, programas de TV, filmes, desenhos animados, entre outros, como alguns dos mecanismos pelos quais os enunciados que constituem o discurso do professor mísero ganham materialidade, tornando-se objeto de reprodução. Navegando por alguns recursos midiáticos encontramos diversos desses enunciados em imagens.

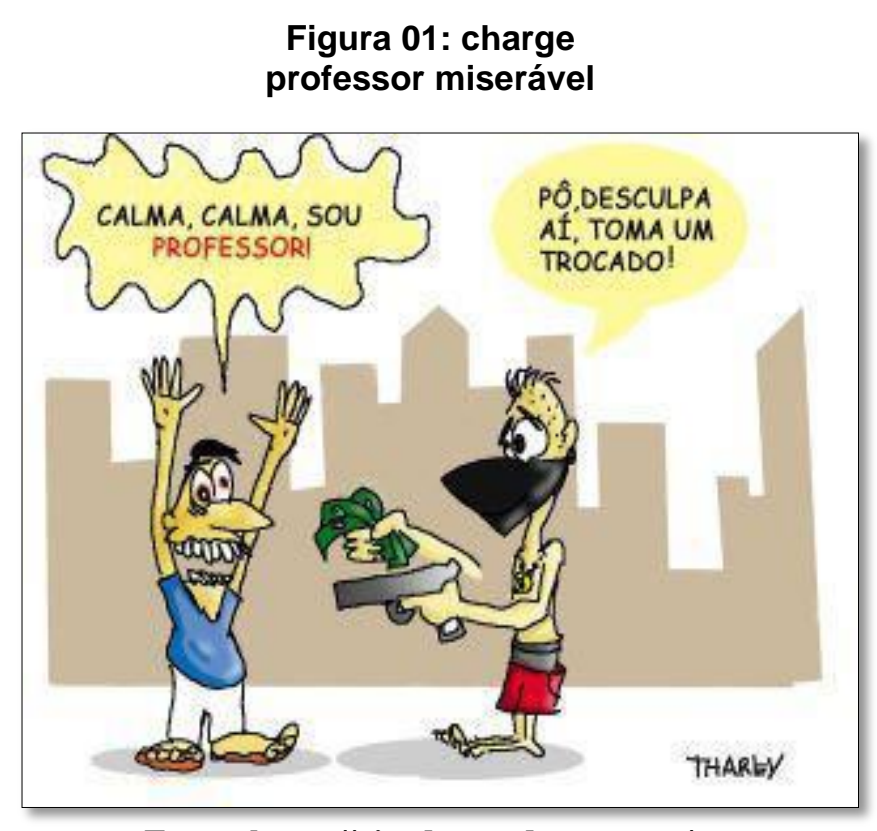

Fonte: $\underline{\text { https://gizadr.wordpress.com/ }}$

A charge acima foi publicada no Blog plaquetas libertina, uma página online construída a partir do modelo de diário, em que a autora disserta sobre temas polêmicos que a atravessam rotineiramente, desde assuntos familiares até aqueles relativos à sua profissão. $\mathrm{O}$ enunciado em questão reproduz de forma irônica a 
imagem do professor miséro, estabelecendo uma relação de verdade, que fornece ao professor o lugar de pobre coitado, mal remunerado, ocupando uma posição inferior em comparação com as demais profissões. Em uma leitura simplória da imagem, vemos o ladrão, "sujeito" que ocupa um lugar de renegado na sociedade, demonstra caridade para com o professor, oferecendo-o seu próprio dinheiro, pois, seguindo esta esteira de pensamento, o professor é pobre, miserável.

Outro enunciado que fomenta o discurso do professor miséro pode ser vislumbrando na animação infantil "Professor também é gente" (uma produção dos estúdios Disney).

Figura 02. Cena da animação professor também é gente.

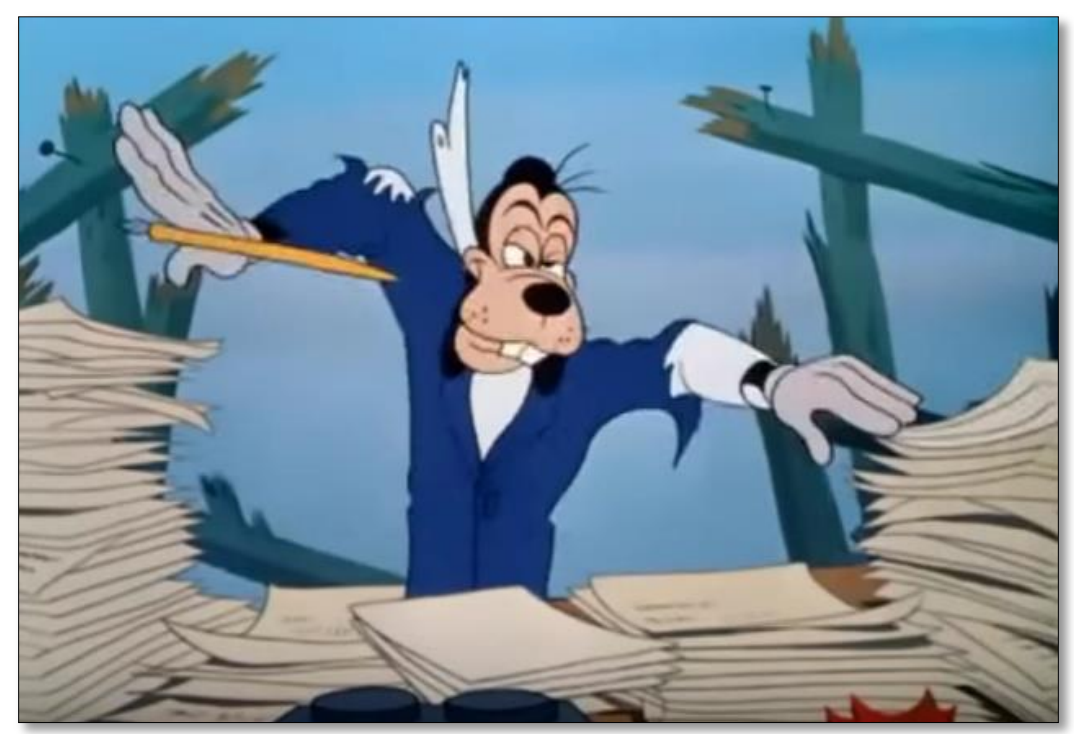

Fonte: https://www.youtube.com/watch?v=ZnlEwrXYYBk

No desenho em questão as cenas são desenroladas por um narrador, que explica de forma bem humorada como é a relação do professor com os alunos na escola. O professor é interpretado pelo famigerado personagem Pateta, que busca a todo custo conduzir sua aula da melhor forma possível. Todavia sua missão é constantemente posta em prova frente ao comportamento inadequado dos alunos que não o respeita, bagunçam o tempo inteiro, inclusive, explodem a escola ao final do episódio. O professor "Pateta" está sempre alheio a essas situações, sua expressão conota tristeza, desespero, angustia. Na cena final, após os alunos serem dispensados para as suas casas, o professor continua na escola, trabalhando na correção de provas, todo rasgado, deformado, arrebentado. 
As cenas se entrelaçam em um tom de comédia hilariante que leva o telespectador a situações de risos, aguçadas, principalmente, pelas lembranças que inevitavelmente nos atravessa. Ora, é inevitável a comparação com nossos tempos de escolas, impossível não lembrar imediatamente daquela turma bagunceira, ou daquele professor desprestigiado, miserável, triste, coitado, desautorizado.

Para Brito (2015) são os enunciados que fabricaram/fabricam professores em todos os tempos, esse conjunto de enunciados constitui determinadas representações do ser professor, nas mídias em questão, os enunciados fazem parte de uma malha discursiva que dão ao professor lugar de mediocridade, miserabilidade.

O grande problema dos aparatos midiáticos, situado no campo dos estudos culturais como "pedagogia cultural", é que eles atuam na pedagogização dos sujeitos, uma vez que eles "ensinam coisas, pois transmitem uma variedade de formas de conhecimentos que são vitais na formação da identidade e da subjetividade" (SILVA, 2016, p. 127). Assim, os enunciados que brotam dos artefatos midiáticos operam uma "naturalização da verdade" os quais podem ser incorporados a prática do sujeito professor.

Segundo Foucault (1996) quando o discurso não é compreendido pela sua historicidade, ele acaba sendo naturalizado pela subjetividade do sujeito, levando-o a seguir as leis que emanam desse discurso, tal movimento é concebido por Foucault como prática discursiva. Além de reproduzir o discurso, o sujeito atua como um disseminador, seja pela linguagem, pela produção midiática autoral ou até mesmo pela sua prática de vida.

Nessa esteira, muitos professores passam a ocupar o lugar de sujeito no discurso, reproduzindo práticas discursivas de um professor Mísero, formatando-as quando necessárias, redefinindo-as, moldando-as e transmitindo-as, em outras palavras, de tanto ouvir que professor é um coitado sofredor, muitos professores aceitam essa identidade, reproduzem e vivem essa prática discursa.

No esforço de tentar elucidar como o discurso do professor miséro pode ser incorporado à subjetividade dos professores, invocamos registros frasais de alunos do curso de Pedagogia UFPA/Altamira, em que ao serem provocados sobre o exercício do professorado, surgiram falas que remete a inferioridade do professor em relação aos demais profissionais. 
Quando penso em ser professor logo me vem em mente: que é desvalorizada pela sociedade

Todos falam que professor é: mal pago, secundário as demais profissões como medicina e direito.

Foram esses aspectos discutidos sobre o que é ser professor no meu curso que me ajudaram a entender: que a nossa graduação é muito romantizada e que ela tem que se voltar mais para triste realidade do que é ser professor na sociedade atual.

A sociedade precisa entender que ser professor é: uma classe tão superior quanto qualquer outra formação. (Alunx 01)

Ainda do discurso dos discentes extraiu-se:

Todos falam que professor é: maluco por trabalhar tanto e ganhar tão pouco. (Alunx 13)

Quando penso em ser professor logo me vem em mente: problemas...

Foram esses aspectos discutidos sobre o que é ser professor no meu curso que me ajudaram a entender: a questão de lidar com a indisciplina e a violência na escola. (Alunx 14)

Quando penso em ser professor logo me vem em mente: o desafio de trabalhar coletivamente. (Alunx 07)

Todos falam que professor é: pobre coitado

Foram esses aspectos discutidos sobre o que é ser professor no meu curso que me ajudaram a entender: mau comportamento, agressão dos alunos. (Alunx 03)

As falas dos alunos vão de encontro com os enunciados que forma o discurso do professor miserável, ele reverbera dentro das licenciaturas de maneira concisa e real. A intenção não é promover uma espécie de juízo de valor da forma correta de ser professor, mas questões como essas, inevitavelmente, nos intrigam por completo, pois elas produzem discursividades, que de tanto serem afirmadas, tornam-se verdades, uma identidade aceita que compõem a subjetividade docente, limitando o professor a um personagem triste e depreciado, podendo atrapalhar na sua prática docente (GARRÉ, 2015).

As subjetividades docentes, assim como qualquer outra, são móveis, e serão influenciadas pelos encontros que o interpela, seja com a cultura, com a mídia, com 
a sala de aula, com o currículo, entre outros (FISCHER, 2001). Assim como toda moeda tem duas faces, o professor, ainda mais que moeda, pode ser multifacetado e, se existe uma subjetividade docente ligado a miserabilidade do professor, o outro lado da moeda também é real e latente, isto é, enquanto discursos produzem um professor Mísero, outros discursos também estão fabricando outras subjetividades docentes, como por exemplo, o professor herói, o novo messias que conduzirá a humanidade no caminho do bem, ruma a uma sociedade mais justa e solidária.

\subsection{O professor, o fabricado, o novo messias}

Ser professor é ser corajoso e dedicado. O condutor de uma sociedade. Meus alunos precisam saber que ser professor é o que farão/ajudarão eles a seguirem enfrente de forma correta na sociedade. A sociedade precisa entender que ser professor é a base para a vida social de seus filhos, onde através dele seus filhos se formarão para o mercado de trabalho e sociedade. (Alunx 05).

O professor é estimulador dos sonhos de seus alunos. A sociedade precisa saber que ser professor é alguém que contribui para uma sociedade mais justa e crítica (Alunx 07)

Acima apresentamos algumas frases de alunos do curso de Pedagogia que colocam em cena a circulação dos discursos que engendram a subjetividade docente, no caso em questão a fabricação do professor messiânico. Nessa subjetividade o professor é adjetivado a partir de um atributo salvacionista, um herói que está para além dos desenhos animados, responsável pela melhoria da qualidade de vida do cidadão, na fala $\mathrm{dx}$ alunx 05 "professor é o que farão/ajudarão os alunos a seguirem enfrente de forma correta na sociedade".

Nessa linha de pensamento o professor messiânico é aquele que irá transpor todas as mazelas sociais que atravessam a escola, superar todas as barreiras e conduzirá seus alunos aos mais altos níveis intelectuais, moldando seu caráter, retirando-os do mundo das drogas, da prostituição, ensinando métodos contraceptivos para erradicar a gravidez na adolescência. A seu dispor está às práticas metodológicas diferenciadas, voltadas para o social, eles são seus "poderes" concebidos durante um curso de licenciatura. Sendo assim, torna-se, de acordo com Silva (2010, p. 189) inspirado em Foucault: 
"um tipo idealizado de professor e que, direta e indiretamente, se relaciona com os discursos institucionalizados, exigindo do professor, que seja um profissional completo e que saiba lidar bem com as adversidades que surgem no terreno de sua profissão".

Ao gerir uma categoria ao sujeito-professor, este é atravessado por identidades e essências que implicam na produção de pensamentos e práticas comportamentais sobre o ser professor, no caso, o ser um herói, para formatar-se aos moldes necessários de uma possível formação de professores oficial, necessária e gerida pelo Estado. O professor, portanto, é formado a partir dos interesses históricos/econômicos/políticos/culturais do Estado em cada tempo, a partir dos discursos que produzidos sobre o ser professor em cada época e lugar.

Os enunciados que integram esses discursos estão pulverizados nos mais diversos artefatos pedagógicos, na pesquisa em tela, o recorte escolhido para movimentar o debate são as mídias digitais. Nelas os enunciados que materializam especificamente o professor messiânico produzem e embaralham os sentidos e significações, nos fazendo "ler, crer e desejar no campo da educação" (CHAVES, 2016, p. 175). Assim, selecionamos algumas imagens compartilhadas em rede que remetem ao discurso desse professor herói:

Figura 03. Acoplado de figuras acerca do professor herói.
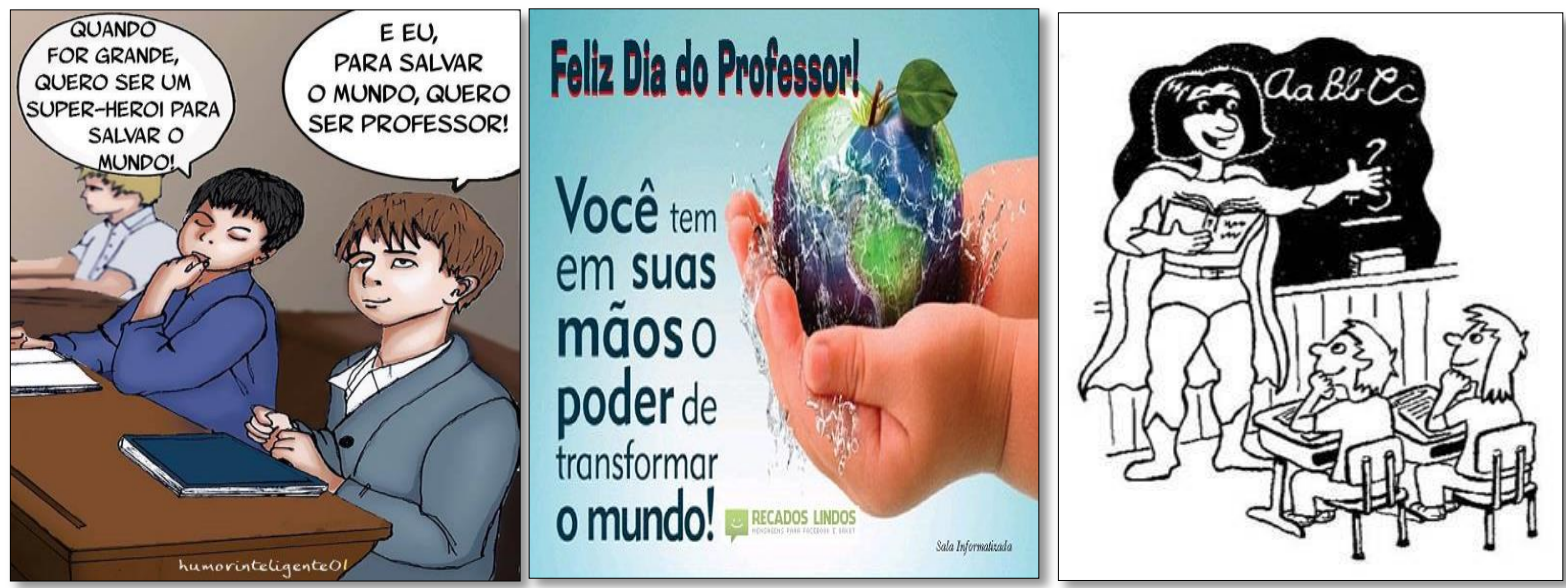

Fonte: http://www.imagemwhats.com.br/feliz-dia-do-professor-imagens-baixar/

No processo de subjetivação docente do professor messiânico, o cinema ganha um destaque especial na reprodução dos enunciados que juntos produzem o 
discurso salvacionista. Tomamos como exemplo o filme "Ao mestre com carinho", produzido na década de 1960, o qual foi estrelado pelo celebre ator Sidney Potier.

No filme o ator principal é um engenheiro, negro, formado recentemente, o qual, na busca por melhoria de vida, parte para a cidade de Londres para lecionar em uma escola. Todavia, nem tudo são flores, a docência tornou-se um verdadeiro desafio para esse personagem, alocado em uma escola da periferia, atravessada por uma infinidade de mazelas sociais, como pobreza, marginalização, violência, prostituição, falta de recursos para a escola.

Figura 04. Cenas do Filme ao Mestre com Carinho.

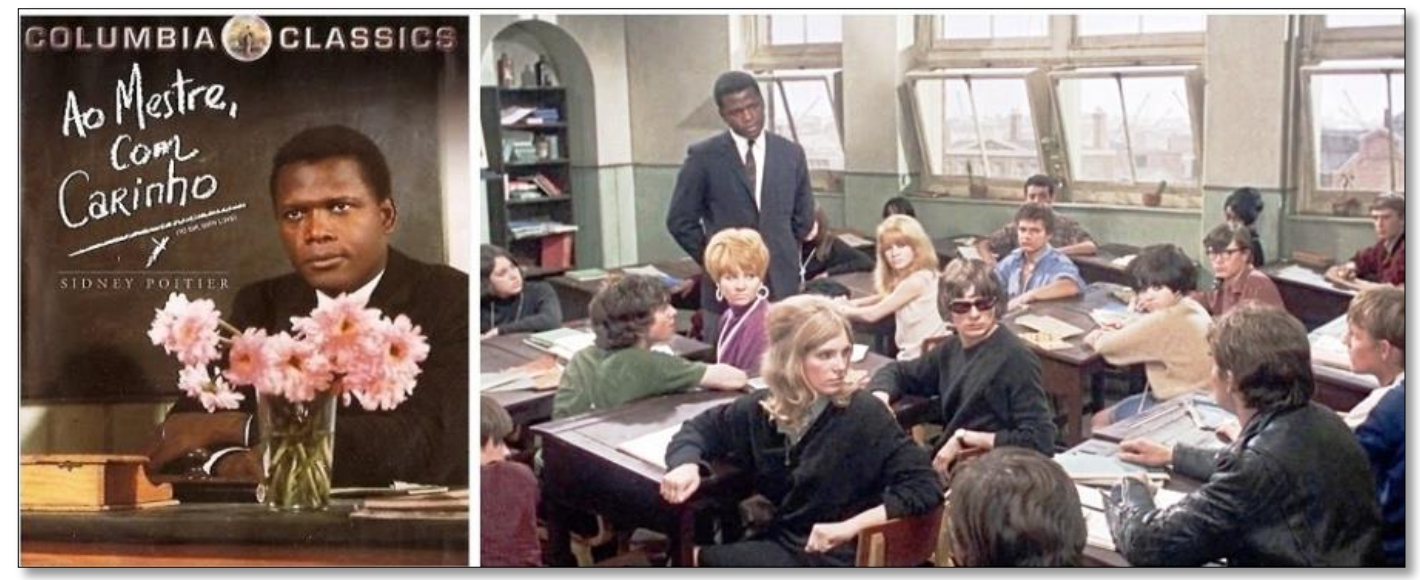

Fonte: https://www.youtube.com/watch?v=TE9iwnDTBRw

Diante da grave situação, o professor percebeu que não adiantava pautar sua prática docente apenas na exposição de conteúdos, era preciso antes discutir com os alunos algumas questões de viés moral e social, ajudá-los a resolver seus problemas com a família, com o crime, com as drogas. Para tanto o professor busca trazer para suas aulas metodologias que estivessem atreladas ao cotidiano daqueles alunos, sempre pontuando os valoreis morais e o uso da educação como ferramenta de mudança de vida.

Figura 05. Cenas do Filme ao Mestre com Carinho/práticas.
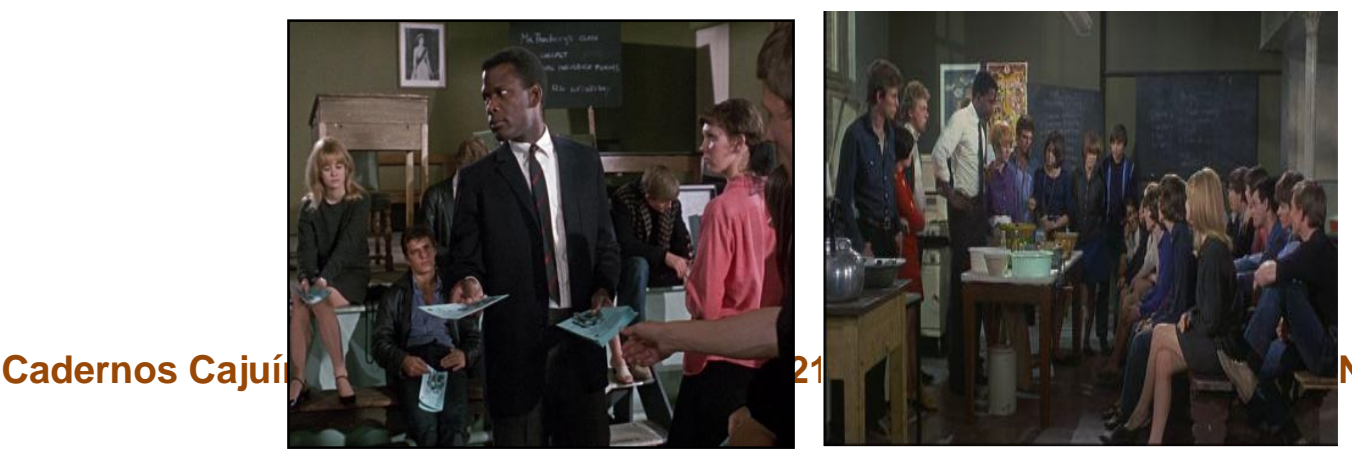
Fonte: https://www.youtube.com/watch?v=TE9iwnDTBRw

A partir da sua prática diferenciada do docente o cenário catastrófico passou a mudar na escola. Alunos mais interessados, participativos, que se afastaram das drogas, da violência. A própria escola começou a mudar de aparência, os alunos pintaram as paredes, as cadeiras, o chão, tornou-se um ambiente limpo e agradável. Os alunos terminaram o ginásio (equivalente ao ensino médio no Brasil) e deram continuidade aos seus estudos na universidade, o professor os salvou, transformou a vida social daqueles sujeitos que estavam esquecidos pelo Estado, libertando-os da marginalidade e da pobreza, levando-os a se tornar cidadãos valorosos.

Impossível assistir a filmes inspiradores como esse e não se emocionar. A trama pode provocar no receptor, falando-se aqui do professor, o desejo de imediatamente correr para uma sala de aula para mudar a vida de crianças e jovens que ainda estão na escola. Ao graduando, o filme pode incitar o desejo de seguir na docência, de usar seus conhecimentos para transformar a realidade social dos alunos.

Está é uma característica interessante do cinema, ele tem a capacidade de sensibilizar o sujeito, produzir sentidos de afetos. O cinema nos faz perceber os mundos, a multiplicidades que nos cercam, ou estão presentes, inclusive, em nós mesmos, tudo isso, também, através de compartilhamento de experiências, eventos e histórias, nos fazendo sentir-se no outro, ou em nós mesmos, exercendo assim, a alteridade (BRITO, 2014; SILVA; COSTA, 2017).

A grande questão por trás desses enunciados são as relações de poder que elas exercem sobre aqueles que não alcançam esse lugar de professor messiânico no discurso. É preciso ter em mente que nem todos os discursos disseminados na sociedade serão alcançados pelo sujeito. Assim como o discurso estabelece o corpo ideal, no ocidente, magro, saudável, musculoso, que não é alcançado por todos, mas desejado, ele também produz o professor ideal, messiânico, herói, o qual não 
será incorporado a prática do sujeito, atuando, portanto, como forma de opressão e exclusão.

A cultura, seja através do cinema ou de outros artefatos midiáticos, acaba por estabelecer entre os seres humanos relações de poder, o qual determina o que é ou não verdade (CHAVES, 2016). A verdade nada mais é do que um discurso aceito por um grupo e reproduzido ao longo do tempo. A lógica é muito simples, Foucault ensina que os discursos são lançados em uma sociedade, ou ele é aceito como verdade ou não, tornando-se, portanto, verdade absoluta. Aqueles que porventura não aceitam essas verdades são taxados como loucos e desviantes (BRITO, 2015), tosquiados por uma censura, na qual os definem como vagabundos, como assim diz Deleuze e Guattari (2012, p. 24):

Você será significante e significado, intérprete e interpretado - senão será desviante. Você será sujeito e, como tal, fixado, sujeito de enunciação rebatido sobre um sujeito de enunciado - senão você será apenas um vagabundo.

As práticas discursivas que colocam o ofício docente como um ato de heroísmo reforçam uma verdade que precisa ser seguida por todos, aqueles que não alcançam tal identidade serão taxados de alguma forma. Esse movimento pode ter relação com o fora, no caso a sociedade, mas também pelo professor que incorpora essa verdade, todavia quando não a alcança, produz em si sentimentos de frustração e culpa.

Dessa forma o professor que não é o herói acaba sendo julgado por todos os lados. É uma lógica perversa que não condena o sistema anacrônico, mas aquele professor que não buscou uma atualização, não se condena as salas de aula abarrotadas de alunos, mas o professor que não utiliza práticas metodológicas diferenciadas, não se condena a violência nas escolas, mas os professores que não dialoga com os alunos. Ao professor herói as honrarias, medalhas, filmes autobiográficos. Já os demais professores, culpados, medíocres, coitados, míseros!

Quando voltamos nossa atenção para a sala de aula, enveredados sob o discurso do professor salvacionista, inevitavelmente nos vem à mente a imagem do professor correto, firme, amigo, aquele que escuta seus alunos, ajuda com suas dificuldades, mas que também trabalha conteúdos de forma didática, prendendo a atenção dos mesmos e, principalmente, alcançando êxito na formação conceitual e cidadã do indivíduo. Assim como a face heroína e miserável do professor foi 
inventada, outras faces são fabricadas diariamente, e quando aceitas, tornam-se verdades difíceis de ser fissuradas.

\section{CONCLUSÃO}

Professor messiânico; professor-miséro, temos também: professorpesquisador; professor-ambiental; professor-reflexivo; professor construtivista; professor-crítico; professor-questionador; professor-filósofo; professor-narrador; professor-cientista; professor-interdisciplinar; professor-divulgador, professorpsicólogo; professor-artista... Poderíamos continuar citando todas as subjetividades/modelos que as pesquisas na área da educação corroboram, mas certamente estaríamos longe de concluir tal lista que aumenta a cada publicação, estudo... Será que precisamos de mais um modelo identitário para o professor? Já há tantos! Como se fosse um traje, em que a partir de um processo formativo (seja ele inicial, contínuo, histórico...) este professor traja-se infinitas vezes. Teria o professor à idoneidade de trajar-se tanto? Por que trajar-se? Talvez não fosse à hora de destrajar-se? Não sabemos! Mas faz-se necessário perguntarmos mais do que responder, pensarmos mais do que apontar!

"Estranhar o que está posto". Quanta potência há nisso, nesta frase, que ainda seria possível acrescentar a terminação "im", pois muitas vezes é im-posto trajes por modismos internacionais, ou grupos de estudos dentro dos cursos de formação de professores. Seja lá qual professor és, ou qual traje estejas travestido, no estranhar há força criadora para quebrar muitos regimes de verdade e entender as visões históricas, inclusive a própria ideia de estranhar e o que estranhar.

As pesquisas que envolvem objeções teóricas, metodológicas e epistemológicas da educação não se encerram aqui, nem os temas propostos a elas. Inventar, não mais trajes, mas caminhos-outros, é extremamente necessário, pois o mundo está em constante itinerância, então ter uma visão histórica, e entender que esta não é linear e se faz necessário.

Pontuar se o discurso é certo ou errado não é essa a intenção e nem seria possível, afinal os discursos podem mudar no decorrer dos tempos e o que é correto hoje pode não ser a manha, mas sim pontuar como somos coagidos por discursos de poder que nos tornam seguidores de modelos. 
Os modelos (im) postos são constantemente produzidos, os saberes são inventados, capturados, desdobrados no/pelo/com mundo. É como nos faz pensar Gilles Deleuze, não estamos no mundo, transformamo-nos com ele, portanto, transformar o (im)posto, não olhar para enxergar, nos faz criar novos (des)caminhos, inventar novas forças ou novas armas" (DELEUZE; PARNET, 1998, p. 5) para a pesquisa educação no Brasil.

\section{REFERÊNCIAS}

BRITO, I. B. Ser professor de ciências e matemática: regimes de verdade e processos de subjetivação. 2015. Dissertação de Mestrado. Universidade Federal do Pará.

BRITO, M. R. O Devir-Mulher De "Orlando" De Virginia Woolf: Uma Leitura Por Estilhaços. ALEGRAR. 2014, v. 2, p. 115-126.

CHAVES, S. N.. Um currículo para despertar adultos e adormecer crianças. In: CHAVES, Sílvia N.; SILVA, Carlos Aldemir F.; BRITO, Maria R.. (Org.). Cultura e Subjetividade: Perspectivas em Debate. 1ed.São Paulo: Editora Livraria da Física, 2016, v. 1, p. 215-226.

DELEUZE, G; PARNET, C. Diálogo. São Paulo: Escuta, 1998.

DELEUZE, G.; GUATTARI, F. Mil Platôs. Vol. 3. São Paulo: Ed. 34, 2012.

FISCHER, R. M. B. O dispositivo Pedagógico da Mídia: modos de educar na e pela TV. Educação e Pesquisa, São Paulo, v 28, n. 1, p. 151-162, jan./jun. 2002.

FOUCAULT, M. A Arqueologia do saber. Rio de Janeiro: Forense, 2012.

FOUCAULT, MI. Ordem do discurso (A). Edições Loyola, 1996.

GARRÉ, B. H. O Dispositivo da Educação Ambiental: modos de constituir-se sujeito na revista Veja. 2015.

GONZÁLEZ REY, F. L. O valor heurístico da subjetividade na investigação psicológica. In: REY, F. L. G. (Org.) Subjetividade, complexidade e pesquisa em psicologia. São Paulo: Thompson Learning. p. 27-51, 2005.

PARAíSO, M. A. Política da subjetividade docente no currículo da mídia educativa brasileira. Educação \& Sociedade, v. 27, n. 94, p. 91-115, 2006.

PARAíSO, M. A. Metodologias de pesquisas pós-críticas em educação e currículo: trajetórias, pressupostos, procedimentos e estratégias analíticas. Metodologias de pesquisas pós-críticas em educação. Belo Horizonte: Mazza Edições, p. 23-45, 2012. 
PELBART, P. P. A vertigem por um fio. São Paulo: lluminuras, 2000.

SANTOS, H. S. S; BRITO, M. R.; SILVA, C. A. S. . Processos de subjetivação no ensino de ciências: a sexualidade para além do sexo biológico no desenho animado 'os pinguins de madagascar'. Revista de Ensino de Biologia da Associação Brasileira de Ensino de Biologia (SBEnBio), v. 9, p. 4878-4887, 2016.

SILVA, C. A. S.; COSTA, D. W. S. Construção de novos olhares a partir do cinema: encenando novas educações, sexualidades e des-gêneros. Diversidade e Educação, v. 5, n. 1, p. 42-50, 2017.

SILVA, T. T. Documentos de identidade: uma introdução às teorias do currículo. In: Documentos de identidade: uma introdução às teorias do currículo. 1999. 